\title{
Influence of Admission Source on the Outcome of Patients in an Intensive Care Unit
}

\author{
Anirban Hom Choudhuri, Mitali Chakravarty, Rajeev Uppal \\ Department of Anaesthesiology and Intensive Care, Govind Ballabh Pant Institute of Postgraduate Medical Education and Research, New Delhi, India
}

\section{Abstract}

\begin{abstract}
Aim of the study: The admission in the Intensive Care Unit (ICU) occurs from various sources, and the outcome depends on a complex interplay of various factors. This observational study was undertaken to describe the epidemiology and compare the differences among patients admitted in a tertiary care ICU directly from the emergency room, wards, and ICUs of other hospitals. Materials and Methods: A retrospective study was conducted on 153 consecutive patients admitted from various sources in a tertiary care ICU between July 2014 and December 2015. The primary endpoint of the study was the influence of the admission source on ICU mortality. The secondary endpoints were the comparison of the duration of mechanical ventilation, length of ICU stay, and the ICU complication rates between the groups. Results: Out of the 153 patients enrolled, the mortality of patients admitted from the ICUs of other hospital were significantly higher than the patients admitted directly from the emergency room or wards/operating rooms $(60.5 \%$ vs. $48.2 \%$ vs. $31.9 \% ; P=0.02)$. The incidence of ventilator-associated lung injury was lower in the patients admitted directly from the emergency room $(23.4 \%$ vs. $50 \%$ vs. $50 \% ; P=0.03)$. Multivariate logistic regression analysis revealed higher age, increased disease severity, longer duration of mechanical ventilation, and longer ICU stay as independent predictors of mortality in the patients shifted from the ICUs of other hospitals. Conclusion: The study demonstrated a higher risk of ICU mortality among patients shifted from the ICUs of other hospitals and identified the independent predictors of mortality.
\end{abstract}

Keywords: Intensive Care Unit admission source, ICU admission score, outcome

\section{INTRODUCTION}

The critically ill patients are admitted to the Intensive Care Unit (ICU) primarily from three sources. They are (i) direct admissions from the emergency or casualty department, (ii) wards or operating rooms within the hospital, and (iii) ICUs of other hospitals.

The clinical spectrum of disease from the different sources is highly variable, and the same has been documented in a wide variety of conditions. ${ }^{[1-3]}$ Studies have also shown that inter-hospital transfer of critically ill patients which occurs due to economic reasons, lack of bed availability and lack of specialized services carries a high risk of mortality and morbidity. ${ }^{[4,5]}$ However, the severity of illness alone does not often predict the risk of adverse outcomes. Even after adjustment for case mix and severity of illness, it has been demonstrated that a complex interplay of various factors contributes to the higher mortality observed in inter-hospital over intra-hospital transfers. ${ }^{[6,7]}$

\begin{tabular}{|l|l|}
\hline \multicolumn{2}{|c|}{ Access this article online } \\
\hline Quick Response Code: & Website: \\
\hline & www.ijccm.org \\
\hline & \\
\hline
\end{tabular}

The objectives of the present study were to describe the epidemiology and compare the differences among patients admitted to the ICU directly from the emergency department, wards, and operating rooms within the hospital or from ICUs of other hospitals.

\section{Materials and Methods}

An observational, retrospective study was conducted in a cohort of 153 consecutively admitted patients in the seven bedded mixed medical-surgical ICU of a 750 bedded tertiary care superspeciality institute affiliated to the University of Delhi between July 2014 and December 2015. Data were

Address for correspondence: Dr. Anirban Hom Choudhuri, Department of Anaesthesiology and Intensive Care, Govind Ballabh Pant Institute of Postgraduate Medical Education and Research, New Delhi - 110002 , India. E-mail: anirban.homchoudhuri@gmail.com

This is an open access article distributed under the terms of the Creative Commons Attribution-NonCommercial-ShareAlike 3.0 License, which allows others to remix, tweak, and build upon the work non-commercially, as long as the author is credited and the new creations are licensed under the identical terms.

For reprints contact: reprints@medknow.com

How to cite this article: Choudhuri $\mathrm{AH}$, Chakravarty $\mathrm{M}$, Uppal R. Influence of admission source on the outcome of patients in an intensive care unit. Indian J Crit Care Med 2017;21:213-7. 
extracted from the hospital ICU database maintained for the administrative and clinical purpose. Approval was sought from the Institution Ethics Committee for waiver of informed consent.

The primary endpoint of the study was the influence of the admission source on ICU mortality. The secondary end points were a comparison of the duration of mechanical ventilation, length of ICU stay, and the ICU complication rates between the groups.

The following admission sources were identified for the purpose of the study:

1. Emergency department

2. Hospital wards and operating rooms

3. ICUs of other hospitals.

All the information were extracted in the data extraction form prepared from the patient's chart available in the ICU for the following variables.

On ICU admission, age, sex, admission source, primary diagnosis, and severity of the underlying medical condition (Acute Physiology and Chronic Health Evaluation [APACHE II]).

On ICU exit, death or discharge, duration of mechanical ventilation, lengths of ICU stay, and complications occurring during stay in the ICU.

The following complications were analyzed-acquisition of multi-drug resistant (MDR) pathogens, occurrence of hospital-acquired pneumonia (HAP), catheter line associated blood stream infections (CLABSI), urinary tract infections (UTIs), and ventilator-associated lung injury (VALI).

VALI was defined as the occurrence of any form of lung injury during mechanical ventilation. It included volutrauma, barotrauma, biotrauma, atelectrauma, shearing injury, and oxygen toxicity. However, the individual types of VALI were not available for analysis.

The primary ICU diagnosis was categorized as follows respiratory diseases, neurological diseases, cardiac diseases, sepsis, and metabolic disorders.

The results were expressed as mean \pm standard deviation for continuous variables, and percentages for categorical variables.
Demographic and disease severity were compared among the three groups, using the Pearson's Chi-square test for categorical variables and one-way analysis of variance for continuous variables. Univariate and multivariate logistic regression analyses were used to investigate the effect of variables on mortality among the patients transferred from ICUs of other hospitals. The variables entered for univariate and multivariate analyses were age, sex, APACHE II score, length of ICU stay, duration of mechanical ventilation, admission source, and presence of ICU complications. $P<0.05$ was considered statistically significant. Statistical analyses were conducted with statistics software (Stata/IC, Stata Corp., College Station, Texas, USA).

\section{RESULTS}

Out of 153 patients included in the study, 47 patients $(30.7 \%)$ were admitted directly from the emergency, 30 patients $(18.9 \%)$ were transferred from the in hospital wards and operating rooms, and 76 patients $(49.7 \%)$ were transferred from ICUs of other hospitals. The admission had male preponderance $(68.6 \%)$ with equal distribution among the groups. There was no difference in terms of age, APACHE II, and primary disease [Table 1] between the groups.

The ICU mortality was significantly higher among the patients transferred from the ICUs of other hospitals although there was no difference in the duration of mechanical ventilation, duration of ICU stay, and the occurrence of ICU complications [Table 2] between the groups.

The occurrence of VALI was significantly lower in the patients admitted from the emergency room [Table 3]. There was no difference in the rate of complications between the groups in terms of acquisition of MDR pathogens, occurrence of ventilator-associated pneumonia, CLABSI, and UTI [Table 3].

Multivariate analysis showed that age above 60 years, APACHE II $>24$ days on mechanical ventilation $>11$ days and duration of ICU stay $>15$ days were independent predictors of mortality among patients who were transferred from ICUs of other hospitals [Table 4].

Table 1: Patient characteristics based on admission source

\begin{tabular}{|c|c|c|c|c|c|}
\hline & \multirow[t]{2}{*}{ Total $(n=153)$} & \multicolumn{3}{|c|}{ Admission source } & \multirow[t]{2}{*}{$P$ between groups } \\
\hline & & Emergency $(n=47)$ & Ward $(n=30)$ & Outside ICU ( $n=76)$ & \\
\hline Age (years), mean \pm SD & $54.76 \pm 18.17$ & $52.19 \pm 20.17$ & $55.93 \pm 13.7$ & $56.26 \pm 18.24$ & 0.86 \\
\hline Sex (male/female) (\%) & $105 / 48(68.62)$ & $33 / 14(70.21)$ & $24 / 5(82.76)$ & $48 / 28(62.34)$ & 0.12 \\
\hline APACHE II (mean \pm SD) & $29.96 \pm 15.25$ & $28.85 \pm 13.66$ & $34.20 \pm 15.2$ & $29.12 \pm 16.19$ & 0.39 \\
\hline Respiratory diseases, $n(\%)$ & $31(20.2)$ & $15(31.91)$ & $3(10)$ & $13(17.1)$ & 0.27 \\
\hline Neurological diseases, $n(\%)$ & $39(25.49)$ & $7(14.89)$ & $8(26.67)$ & $24(31.57)$ & 0.36 \\
\hline Cardiac diseases, $n(\%)$ & $16(10.45)$ & $3(6.38)$ & $6(20.0)$ & $7(9.21)$ & 0.57 \\
\hline Sepsis, $n(\%)$ & $50(32.67)$ & $16(34.04)$ & $9(30.0)$ & $25(32.89)$ & 0.29 \\
\hline Metabolic diseases, $n(\%)$ & $17(11.11)$ & $6(12.76)$ & $4(13.33)$ & $7(9.21)$ & 0.76 \\
\hline
\end{tabular}

APACHE: Acute Physiology and Chronic Health Evaluation, SD: Standard deviation; ICU: Intensive Care Unit 


\begin{tabular}{|c|c|c|c|c|}
\hline & Emergency $(n=47)$ & Ward $(n=30)$ & Outside $(n=76)$ & $P$ \\
\hline ICU mortality, $n(\%)$ & $15(31.91)$ & $14(48.27)$ & $46(60.52)$ & $0.02 *$ \\
\hline Duration of mechanical ventilation (mean $\pm \mathrm{SD}$ ) & $9.1 \pm 2.3$ & $7.4 \pm 4.6$ & $11.4 \pm 5.5$ & 0.27 \\
\hline Duration of ICU stay (mean \pm SD) & $14.2 \pm 6.9$ & $11.7 \pm 6.1$ & $19.3 \pm 7.7$ & 0.31 \\
\hline ICU complications, $n(\%)$ & $28(59.57)$ & $22(75.86)$ & $49(64.47)$ & 0.14 \\
\hline
\end{tabular}

SD: Standard deviation; ICU: Intensive Care Unit; $* P<0.05$ significant

\begin{tabular}{|c|c|c|c|c|c|}
\hline & Emergency $(n=47)$ & Ward $(n=30)$ & Outside $(n=76)$ & Total $(n=153)$ & $P$ \\
\hline MDR, $n(\%)$ & $15(31.91)$ & $13(44.83)$ & $24(31.17)$ & $52(33.98)$ & 0.39 \\
\hline HAP, $n(\%)$ & $15(31.91)$ & $13(44.83)$ & $25(32.47)$ & $53(34.64)$ & 0.44 \\
\hline CLABSI, $n(\%)$ & $16(34.04)$ & $9(31.03)$ & $33(42.86)$ & $58(37.91)$ & 0.43 \\
\hline UTI, $n(\%)$ & $14(29.79)$ & $12(41.38)$ & $36(46.75)$ & $62(40.52)$ & 0.17 \\
\hline VALI, $n(\%)$ & $11(23.40)$ & $15(50.0)$ & $38(50.0)$ & $64(41.83)$ & $0.03 *$ \\
\hline
\end{tabular}

MDR: Multidrug-resistant pathogens; HAP: Hospital-acquired pneumonia; CLABSI: Catheter line associated blood stream infections; UTI: Urinary tract infections; VALI: Ventilator-associated lung injury; ${ }^{*} P<0.05$ significant

\begin{tabular}{|c|c|c|c|c|c|}
\hline \multirow[t]{2}{*}{ Variable } & \multirow[t]{2}{*}{ Alive $(n=30)$} & \multirow[t]{2}{*}{ Dead $(n=46)$} & \multirow[t]{2}{*}{$P$} & \multicolumn{2}{|c|}{$95 \% \mathrm{Cl}$} \\
\hline & & & & Unadjusted OR & Adjusted OR \\
\hline \multicolumn{6}{|l|}{ Sex, $n(\%)$} \\
\hline Male & $21(70.00)$ & $29(63.04)$ & 0.87 & 1.3 & 1.4 \\
\hline Female & $9(30.00)$ & $17(36.96)$ & & $0.94(0.48-1.87)$ & $0.64(0.23-1.81)$ \\
\hline \multicolumn{6}{|l|}{ Age, $n(\%)$} \\
\hline$<60$ & $18(50.00)$ & $15(37.50)$ & 0.007 & 1.9 & 1.2 \\
\hline$\geq 60$ & $18(50.00)$ & $25(62.50)$ & & $0.40(0.20-0.79)$ & $0.47(0.17-1.23)$ \\
\hline \multicolumn{6}{|c|}{ APACHE II on admission, $n(\%)$} \\
\hline$<24$ & $17(48.57)$ & $15(36.58)$ & 0.02 & 1.6 & 1.3 \\
\hline$\geq 24$ & $18(51.43)$ & $26(63.42)$ & & $4.43(1.89-10.37)$ & $5.88(1.97-17.5)$ \\
\hline \multicolumn{6}{|l|}{ Days in ICU, $n(\%)$} \\
\hline$<15$ days & $21(67.74)$ & $19(42.22)$ & 0.002 & 1.2 & 1.6 \\
\hline$\geq 15$ days & $10(32.26)$ & $26(57.78)$ & & $0.30(0.14-0.66)$ & $0.41(0.05-2.93)$ \\
\hline \multicolumn{6}{|c|}{ Days on mechanical ventilation, $n(\%)$} \\
\hline$<11$ days & $19(55.89)$ & $21(50.00)$ & 0.016 & 1.9 & 2.2 \\
\hline$\geq 11$ days & $15(44.11)$ & $21(50.00)$ & & $0.42(0.21-0.85)$ & $1.00(0.14-7.02)$ \\
\hline \multicolumn{6}{|l|}{ Cause of admission, $n(\%)$} \\
\hline Lack of facilities & $12(34.28)$ & $16(39.02)$ & 0.08 & 0.8 & 0.9 \\
\hline Lack of bed availability & $6(17.14)$ & $13(31.70)$ & & $1.75(0.69-4.47)$ & $1.82(0.43-7.68)$ \\
\hline Financial reason & $17(48.57)$ & $12(29.26)$ & & $1.53(0.64-3.63)$ & $1.35(0.34-5.41)$ \\
\hline
\end{tabular}

OR: Odds ratio; CI: Confidence interval; APACHE: Acute Physiology and Chronic Health Evaluation

\section{Discussion}

The results of our study confirm that patients transferred to a tertiary care ICU from other ICUs are at high risk for ICU mortality, and the subgroup of patients with age above 60 years, admission APACHE II score more than 24, duration of mechanical ventilation more than 11 days, and length of ICU stay more than 15 days carry the highest probability of ICU death. This was despite the groups having no difference between them in case mix, disease severity on admission, duration of mechanical ventilation and length of ICU stay. The patients transferred from emergency room to the ICUs had lower VALI although the other complication rates, namely, HAP, CLABSI, infection due to MDR pathogens and UTIs were similar between the groups. The contribution of VALI to the all-cause mortality or survival in the groups could not be ascertained from available data.

Critically, ill patients often need specialized care which is offered in the tertiary referral centers. With technological progress, the transfer of medically unstable sick patients from secondary and primary level health-care institutions is becoming more and more frequent and challenging. However, the adverse effects of admitting critically ill patients from the 
ICUs of other hospitals have been previously reported, and their effects on the referral center's benchmark measures have been discussed time and again..$^{[8-11]}$ Although the reasons for their increased mortality are unclear, a combination of various factors including intrinsic patient differences, transfer process, and the lead time bias for the receipt of initial care at the referral hospital are commonly implicated. ${ }^{[12]}$ Flabouris et al. found a higher mortality in patients with multiple trauma, respiratory infection, intracranial hemorrhage, brain trauma injury, and cardiac arrest and lower hospital mortality in patients with drug overdose or chronic obstructive pulmonary disease. ${ }^{[13]}$ Although there is no denying fact that the maximum benefits are likely to be accrued by early transfer, it is also observed that a reasonable degree of clinical stability must be ensured and judicious planning of resources must be undertaken before shifting the patient to achieve success. ${ }^{[14]}$ The same has been reinforced in our study not only by a demonstration of increased mortality among the ICU transferred patients, but identification of the characteristics namely, older age, sickness, longer duration of ICU stay, and mechanical ventilation as independent predictors of mortality in the subgroup of such patients. The understanding of these factors associated with unfavorable outcomes can help the clinicians do a risk-benefit assessment before referring patients to tertiary care ICUs.

In a study of 180 transports in critically ill children, it was found that major corrective procedures were required in $34.4 \%$ of mechanically ventilated children as against only $9.5 \%$ of the nonventilated children. ${ }^{[15]}$ It was also seen that the physiological deterioration and requirement of major intervention were associated with higher therapeutic intervention severity score and longer duration of patient transport. However, many studies did not found such an association. However, the studies finding such a lack of association also did not take into account the degree of stabilization achieved in the initial center nor compared the degree of stabilization or goals achieved before the actual ICU admission in the referral center. ${ }^{[16,17]}$ Such studies are further limited by the presence of referral bias for sicker patients at a greater risk of long distance transfer without achieving the satisfactory level of stabilization.

The decreased occurrence of VALI in patients shifted from the emergency room to the ICU emphasizes not only the effects of ventilation modes and the ventilator used during transport on the outcome but also the importance of respiratory monitoring during such transport. Gervais et al. compared blood gas variables during transport of 30 ventilator-dependent patients who were ventilated using either a manually operated ventilation bag with or without a volume meter at the exhalation valve of the bag, or a time-cycled, volume-constant, portable ventilator. ${ }^{[18]}$ They found that the patients with manual ventilation alone or the transport ventilator were significantly hyperventilated, as opposed to those in whom a volume meter was used to control manual ventilation. This finding was reflected by an increase in $\mathrm{pH}$ in the former two groups. Our data lacked information about the type of ventilation used in patients who were shifted on ventilators and hence we could not draw any conclusion to that effect. However, it is admissible that patients who were shifted from the wards or the emergency department to the ICU spent a lesser time on transport ventilation in comparison to their counterparts shifted from ICUs of other hospitals. In one prospective observational study addressing the prolonged effects of an intrahospital transfer on respiratory function of critically ill patients, majority of the patients showed a significant decrease in partial arterial oxygen tension fractional inspired oxygen ratio $\left(\mathrm{PaO}_{2} / \mathrm{FiO}_{2}\right)$ of 267 at baseline to $2201 \mathrm{~h}$ after transport. Even $24 \mathrm{~h}$ later, a slight deterioration was still present. ${ }^{[19]}$

However, our study had certain limitations. One, our study could not stratify patients based on the time spent on mechanical ventilation in the previous ICU and during transport. This is a critical determinant of the risk of VALI and can limit the validity of our interpretation. Two, the type of ventilators and monitors used in their previous ICUs were variable, and the calculation of disease severity based on APACHE II was dependent on several parameters derived from those ventilators and monitors. This can introduce observer bias. Three, the patients shifted from the ward and emergency room to the ICU have a variable waiting period for admission depending on bed availability in the ICU during which time they are subject to various therapeutic interventions whose details could not be retrieved for analysis. Fourth, certain acute complications such as hypotension, bleeding, and arrhythmias which are common during inter-hospital patient transfers were not encountered in the tertiary ICU because of prior stabilization of such patients in the emergency room. Fifth, the lead time for transfer to tertiary care ICU and also the data on preexisting hospital acquired infection was not available for analysis. Finally, all the drawbacks inherent in a retrospective study design are possible in our study.

\section{ConcLusion}

Our study demonstrated a particular risk for mortality among patients shifted from the ICUs of other hospitals to a tertiary care ICU than patients shifted from the other areas of the hospital and higher age, increased severity of illness, longer duration of mechanical ventilation, and longer ICU stay were the independent predictors of such mortality. However, larger multicentric studies with adequate measures for disease stratification and risk adjustment are necessary to provide more useful information.

\section{Financial support and sponsorship}

Nil.

\section{Conflicts of interest}

There are no conflicts of interest.

\section{RefEREnCES}

1. Odetola FO, Rosenberg AL, Davis MM, Clark SJ, Dechert RE, Shanley TP. Do outcomes vary according to the source of admission to the pediatric Intensive Care Unit? Pediatr Crit Care Med 2008;9:20-5. 
2. Hill AD, Vingilis E, Martin CM, Hartford K, Speechley KN. Interhospital transfer of critically ill patients: Demographic and outcomes comparison with nontransferred Intensive Care Unit patients. J Crit Care 2007;22:290-5.

3. Duke GJ, Green JV. Outcome of critically ill patients undergoing interhospital transfer. Med J Aust 2001;174:122-5.

4. Kerr HD, Byrd JC. Community hospital transfers to a VA medical center. JAMA 1989;262:70-3.

5. Schiff RL, Ansell DA, Schlosser JE, Idris AH, Morrison A, Whitman S. Transfers to a public hospital. A prospective study of 467 patients. N Engl J Med 1986;314:552-7.

6. Mackenzie PA, Smith EA, Wallace PG. Transfer of adults between Intensive Care Units in the United Kingdom: Postal survey. BMJ 1997;314:1455-6

7. Escarce JJ, Kelley MA. Admission source to the medical Intensive Care Unit predicts hospital death independent of APACHE II score. JAMA 1990;264:2389-94.

8. Dragsted L, Jörgensen J, Jensen NH, Bönsing E, Jacobsen E, Knaus WA, et al. Interhospital comparisons of patient outcome from intensive care: Importance of lead-time bias. Crit Care Med 1989;17:418-22.

9. Durairaj L, Will JG, Torner JC, Doebbeling BN. Prognostic factors for mortality following interhospital transfers to the medical Intensive Care Unit of a tertiary referral center. Crit Care Med 2003;31:1981-6.

10. Gordon HS, Rosenthal GE. Impact of interhospital transfers on outcomes in an academic medical center. Implications for profiling hospital quality. Med Care 1996;34:295-309.

11. Rosenberg AL, Hofer TP, Strachan C, Watts CM, Hayward RA. Accepting critically ill transfer patients: Adverse effect on a referral center's outcome and benchmark measures. Ann Intern Med 2003;138:882-90

12. Combes A, Luyt CE, Trouillet JL, Chastre J, Gibert C. Adverse effect on a referral Intensive Care Unit's performance of accepting patients transferred from another Intensive Care Unit. Crit Care Med 2005;33:705-10

13. Flabouris A, Hart GK, George C. Outcomes of patients admitted to tertiary Intensive Care Units after interhospital transfer: Comparison with patients admitted from emergency departments. Crit Care Resusc 2008;10:97-105

14. Golestanian E, Scruggs JE, Gangnon RE, Mak RP, Wood KE. Effect of interhospital transfer on resource utilization and outcomes at a tertiary care referral center. Crit Care Med 2007;35:1470-6.

15. Wallen E, Venkataraman ST, Grosso MJ, Kiene K, Orr RA Intrahospital transport of critically ill pediatric patients. Crit Care Med 1995;23:1588-95.

16. Szem JW, Hydo LJ, Fischer E, Kapur S, Klemperer J, Barie PS High-risk intrahospital transport of critically ill patients: Safety and outcome of the necessary "road trip". Crit Care Med 1995;23:1660-6.

17. Hurst JM, Davis K Jr., Johnson DJ, Branson RD, Campbell RS, Branson PS. Cost and complications during in-hospital transport of critically ill patients: A prospective cohort study. J Trauma 1992;33:582-5.

18. Gervais HW, Eberle B, Konietzke D, Hennes HJ, Dick W. Comparison of blood gases of ventilated patients during transport. Crit Care Med 1987;15:761-3.

19. Waydhas C, Schneck G, Duswald KH. Deterioration of respiratory function after intra-hospital transport of critically ill surgical patients. Intensive Care Med 1995;21:784-9. 